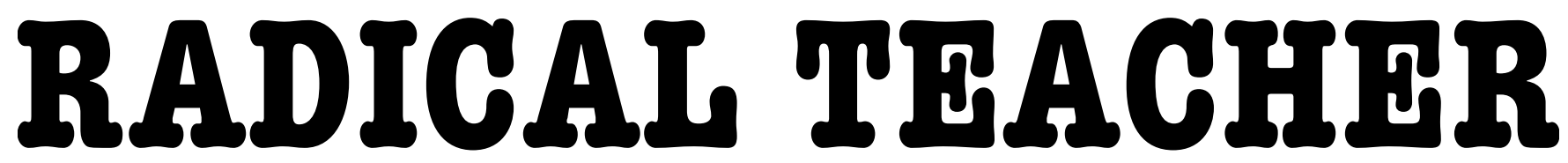
A SOCIALIST, FEMINIST, AND ANTI-RACIST JOURNAL ON THE THEORY AND PRACTICE OF TEACHING

\title{
A Different Third R: Radical Math
}

by Marilyn Frankenstein

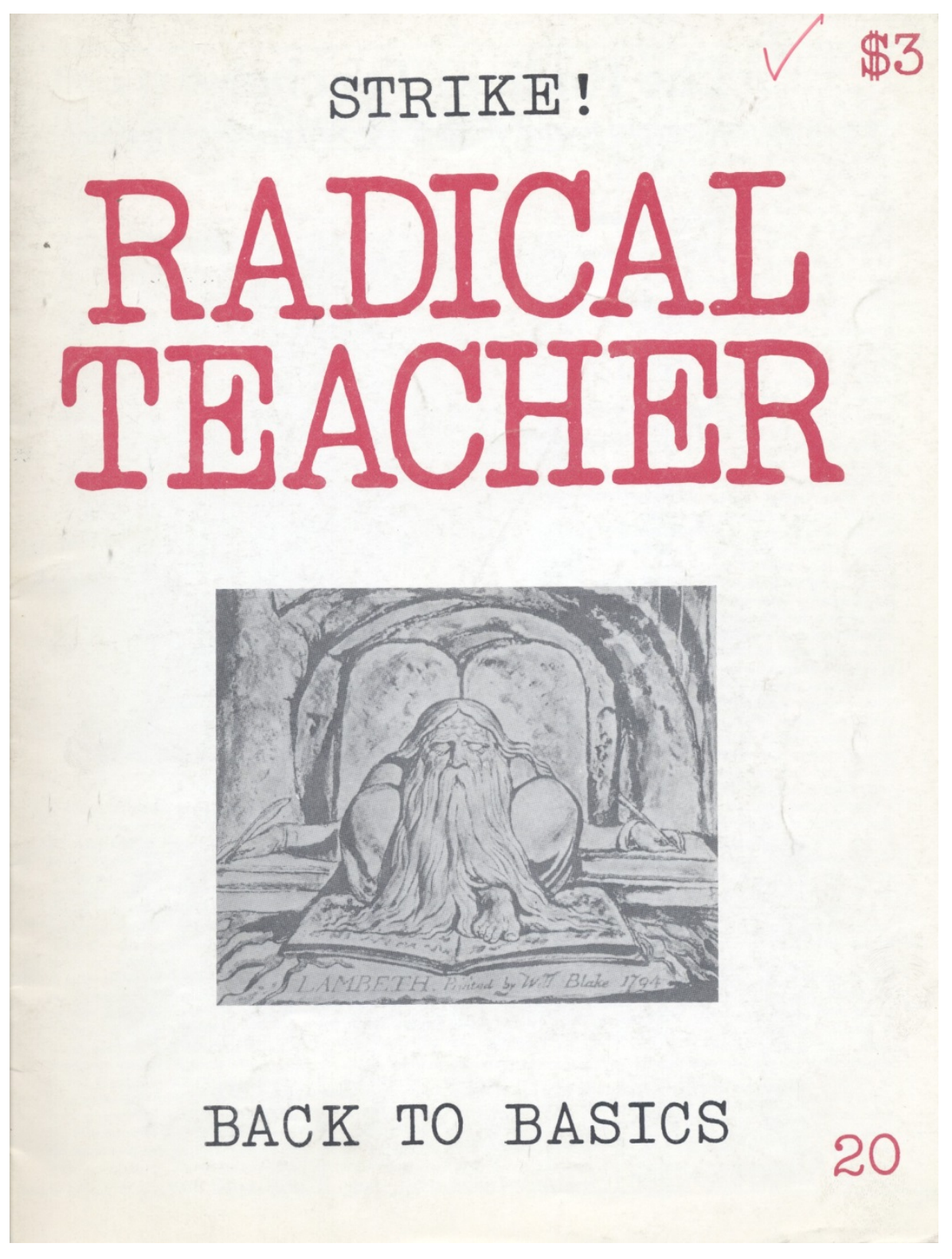


M athematical literacy is more than the ability to calculate. It is the ability to reason quantitatively, the ability to use numbers to clarify issues and to support or refute opinions. Yet the proliferation of arithmetic courses at the college level is evidence that people are not learning even basic computation skills in school. Too many adults cannot use numbers effectively in their daily lives. This article will briefly examine the causes of this situation and will outline a basic arithmetic course that not only teaches adults math effectively, but raises their political consciousness and empowers them to analyze and question the status quo, and to fight back.

The reasons why people aren't learning math involve the scandals of education in our society: too many teachers babysit instead of helping students learn; too many teachers convey their own hatred or fear of math to their students; the math curriculum is irrelevant to students' lives; the math curriculum is boring. More complex reasons involve the scandals of our society: sexual stereotyping leads many women to believe that learning math undermines their femininity; intellectual stereotyping leads many people to believe that learning math is too hard for them; meaningless, boring school work serves to prepare people for meaningless, boring jobs.

Underlying all these scandals is the fact that the ruling class can more effectively keep people oppressed when these people cannot break through the numerical lies and obfuscations thrown at them daily. A mathematically illiterate populace can be lulled by the media into believing, for example, that racism is disappearing, for it will not think

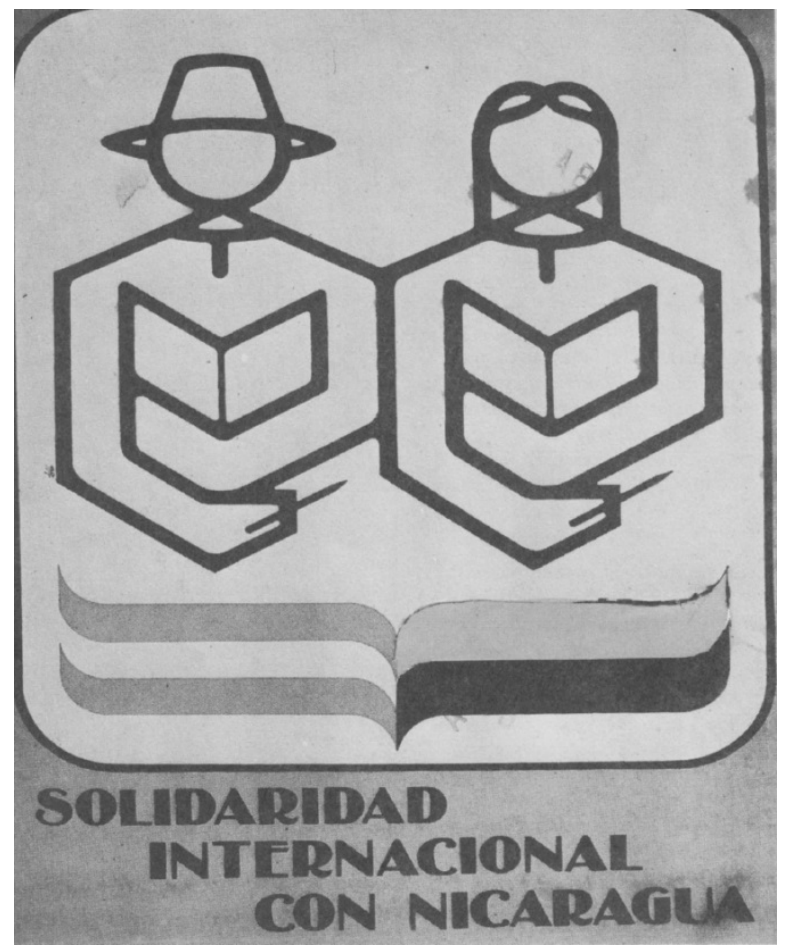

minimally proficient in basic math and able to get somewhat better paying jobs than those who can't pass math skills competence tests. But they do not help people learn to think critically or to use numbers in their daily lives. At worst, they train people to follow rules obediently, without understanding, and to take their proper place in society, without questioning.

The radical math literacy course which I will describe is based on the idea, expressed by Freire, that illiterates "are not marginal to the structure [of society], but oppressed . . . within it. Alienated . . . they cannot overcome their dependency by 'incorporation' into the very structure responsible for their dependency. There is no other road to humanization - theirs as well as everyone else's - but authentic transformation of the dehumanizing structure. ${ }^{\prime 3}$ The content of this course teaches arithmetic while simultaneously raising political consciousness. Its methods try to break down traditional authoritarian teacher-student relationships by giving students meaningful control over their learning process. The aim of the course is to educate people to want radical social change while giving them both the math literacy tools necessary to challenge ruling ideas and the cooperative learning experiences necessary to create and live in a new society.

Education is never neutral. Traditional education and daily life bombard students with oppressive pro-capitalist ideology. A trivial application like totaling a grocery bill carries the non-neutral message that paying for food is natural. Even traditional math courses which provide no real life data carry the hidden message that learning math has nothing to do with learning to understand and control the world. Radical to answer back that median black income was 61 percent of median white income in 1969 and only 57 percent in 1977, that official black youth unemployment was 45 percent in 1979 compared to 16 percent for white youth, or that nonwhite infant mortality rates were 21.7 per 1,000 births in 1977 compared to 12.3 per 1,000 births for whites. When promoters of nuclear energy argue that nuclear power plants provide 12 percent of our electricity, only a mathematically sophisticated populace could counter that nuclear energy provides just 3 per cent of our total energy needs. ${ }^{1}$

Most college arithmetic courses emphasize rote computation drills and word problems whose solutions fit a few simple patterns. They are based on what Paulo Freire calls "banking" methods: "expert" teachers deposit knowledge in the presumably blank minds of their students; students memorize the required rules and expect future dividends. ${ }^{2}$ At best, such courses make people courses such as this try to show that there is another point of view. I believe the best we can do as teachers is to tell students our own biases and encourage them to use numbers to support whatever opposing views they hold. ${ }^{4}$ By having students examine issues quantitatively and by providing data that most students would not otherwise obtain, we are not feeding students propaganda, but helping them to think critically and to ask incisive questions about the conditions of society.

\section{CONTENT}

In this radical math course, arithmetic skills are learned through political application. ${ }^{5}$ In addition to raising students' political consciousness by using numbers to expose the inequalities and insanities in our society, the content of this course provides many other political benefits. 
First, class discussions which use math to analyze complex, adult issues increase students' intellectual selfimage. Touching on a wide variety of topics adds to the students' background knowledge and therefore improves their ability to argue effectively. As students gain confidence in their own intelligence, they become more willing to voice their opinions and challenge what they have been taught.

Second, radical math is an ideal subject for practicing the slow, careful thinking that people need to examine critically the structure of our society. Because a math text must be read slowly, by filling in steps between the lines, students are forced to slow down their intake of information. Because small visual changes in the symbols can totally change the meaning of a mathematical expression, students are forced to slow down their perceptions. Because the political application problems in this course either contain more information than needed, or require finding additional information, students get practice examining and searching for data, rather than immediately spitting out an answer. And because this course asks students to formulate their own math problems, they get practice examining the consequences of many possible situations before determining what questions they can ask and answer.

Third, since the applications come from a wide variety of areas, it is more than likely that students will raise subject matter questions that the teacher cannot answer. This provides students with an important experience: realizing that the teacher is not an "expert" with all the answers. It encourages students to become skilled at searching for information to answer their own questions. Thus, students become what Freire calls "critical coinvestigators in dialogue with the teacher. ${ }^{\prime 6}$

Finally, radical math challenges the fragmented view of society presented by a traditional curriculum which breaks knowledge into separate, unrelated issues to be discussed only by specialists. When math is taught as a necessary part of a careful analysis of the conditions of society, students have a clear example of how knowledge of specific subjects can be integrated to give a critical understanding of the world.

The following sample problems illustrate how to integrate the teaching of basic mathematics with the raising of political consciousness, and how to foster critical thinking by expanding traditional problem-solving techniques to include definition of problems and gathering of required information. ${ }^{7}$

\section{Applications of Operations with Decimals}

According to the Boston Globe (27 Dec., 1980), an unpublished Department of Energy study states that since its beginning nuclear power has benefited from federal aid in five major areas: $\$ 23.6$ billion for research and development, $\$ 237.4$ million to promote foreign reactor sales, $\$ 2.5$ billion for uranium market promotion, $\$ 7.1$ billion in fuel enrichment pricing aid, and $\$ 6.5$ billion for management of wastes, mining spoils cleanup, and unpaid decommissioning costs.
1. Find the total federal subsidy to the nuclear power industry.

(This additional problem requires understanding how decimals are used with the words "million" and "billion." It can also help improve students' intuitions about large numbers. A powerful way of describing the gigantic amount, $\$ 40$ billion, is to have the class compute that, spending at the rate of $\$ 1,000$ per hour, it would take over one hundred years to spend just $\$ 1$ billion! There are many good charts, put out by organizations like SANE, that give specifics on how much in human services our nuclear power and nuclear armament spending costs us.)

2. (a) Write a brief statement of your opinion about nuclear power. (b) Work in a group with three or four others who have similar opinions. List the kinds of numerical data that would support your opinion. (c) Find at least one of the facts that you feel would support your opinion and describe how you would find the others.

(The goal of this exercise is to make students aware of how people find and use numbers to support their arguments. For example, this study reported that without these subsidies nuclear power would be twice as costly [4.7\$ per kwh] and unable to compete with oil-fired electricity, currently the most expensive power $[3.75 \$$ per kwh].

\section{Applications of Percent}

According to "Eating Better for Less" by Lucille Sandwith (Food Monitor, Sept.-Oct., 1980, pp. 8-12), fifty out of the 32,000 U.S. food manufacturing firms make 75 percent of the net profits. Of these top fifty corporations, thirty-one bought 63 percent of the national media advertising, or roughly $\$ 5$ billion in 1977 . Of the top twenty-five advertisers from all industries, eighteen were food companies.

1. What percent of the U.S. food manufacturing firms make 75 percent of the net profits?

(This question requires careful reading since the many given percents might be confused with the percent asked for. And its solution serves a purpose: changing 50/32,000 to 0.2 percent highlights the fact that only a tiny percent of the firms make most of the profits. The information in the question can lead to a political discussion of agribusiness and corporate monopoly in general, as well as to a mathrelated discussion of the advertising industry [70 per cent of television food advertising, for example, promotes low nutrient, high calorie foods, whereas only 0.7 percent promotes fresh fruits and vegetables].)

2. Based on the information given, create and solve a math problem whose solution involves using percents.

(Students will fully understand percents when they understand which percent problems can be created from given information. For example, here students must realize that you cannot find out how much profit the top fifty firms make, but you can find out how much money is spent on national media advertising. Also, it is unclear whether the national media advertising figure refers to the total spent 
by food manufacturing firms or by all industries. Students must find more information in order to clarify this.)

3. Read the entire article (on reserve at the library). Discuss at least three points in the article that are supported by the use of percents.

\section{Applications of Signed Numbers}

According to research done by the Coalition for Basic Human Needs in April, 1980, the AFDC welfare grant provides $\$ 140$ per month for shelter costs: $\$ 96.20$ for rent, $\$ 26.30$ for fuel, and $\$ 17.50$ for gas and electricity. Actual shelter costs in every major Massachusetts city exceed that allowance. This means that to live on the welfare budget you must go into debt. Fill in the following chart, which compares the AFDC debts in various cities in Massachusetts:

(This can lead to a political discussion of poverty in this country and the role of welfare in band-aiding the

$\begin{array}{lrccccc}\text { City } & \begin{array}{c}\text { Actual Average } \\ \text { Rent(a) }\end{array} & \begin{array}{c}\text { AFDC Rent } \\ \text { Debt }\end{array} & \begin{array}{c}\text { Actual } \\ \text { Utillty(b) }\end{array} & \begin{array}{c}\text { AFDC Utillty } \\ \text { Debt }\end{array} & \begin{array}{c}\text { Actual } \\ \text { Fuel(c) }\end{array} & \begin{array}{c}\text { AFDC Fuel } \\ \text { Debt }\end{array} \begin{array}{c}\text { Total Monthly } \\ \text { AFDC Debt }\end{array} \\ \text { Boston } & \mathbf{S 1 4 3 . 1 3} & -46.93 & 47.79 & & 64.08 & \\ \text { Brockton } & 95.99 & & 43.93 & & 64.08 & \\ \text { Cambridge } & 192.43 & & 40.49 & 64.08 & \\ \text { Fitchburg } & 76.23 & & 45.69 & 64.08 & \\ \text { Lawrence } & 78.91 & & 41.01 & 64.08 & \\ \text { New Bedford } & 74.90 & +21.30 & 38.02 & 64.08 & \\ \text { Pittsfield } & 108.05 & & 36.87 & 64.08 & \\ \text { Springfield } & 87.58 & & 39.34 & 64.08 & \end{array}$

(a)Based on 1970 U.S. Census Bureau data for poverty families

(b)Based on rates for $355 \mathrm{kwh}$ electricity and $2.5 \mathrm{mcf}$ gas usage

(c)Based on actual degree days in Massachusetts

problems of our economic system. Statistics which show the disproportionate percent of nonwhite and female heads of poverty families can broaden the discussion to include the economics of racism and sexism. Also, using research done by local political action groups can broaden students' ideas about how to collect information outside libraries, and may even encourage students to get involved working with a particular group.)

\section{METHODS}

Because, as Freire says, "a project's methods cannot be dichotomized from its content and objectives, as if methods were neutral and equally appropriate for liberation or domination, ${ }^{8}$ new methods, as well as content, are important in teaching a radical math course.

Traditional teaching methods convince students that they are stupid and inferior because they can't do arithmetic, that they have no knowledge to share with others, and that they are cheating if they do their school work with others. Such methods effectively prepare students to compete for work at boring jobs over which they have no control.

The methods that follow are intended to begin to undo the training students have received from traditional schooling, to give students a positive intellectual selfimage, and to encourage them to work together to accomplish the task at hand. The techniques are most effective when the reasons behind them are discussed in class.

\section{Analyzing Error Patterns}

All wrong answers (except those guessed wildly from pure anxiety) involve some correct, logical reasoning. For example, there is logical thinking behind these incorrect subtractions:

$\begin{array}{rrr}95 & 64 & 82 \\ -48 & -29 & -36 \\ 53 & 45 & 54\end{array}$

This person realized that you subtract each place value column separately and that you must subtract smaller numbers from larger numbers. However, he didn't know how to "borrow," so he guessed by subtracting the only way he could imagine. The class not only analyzes this student's reasoning, but also discusses how to convince him that the method was wrong and how to teach him correct methods. ${ }^{9}$ Analyzing error patterns provides nonrote reinforcement of computation skills, and shows students that you respect their intelligence and will not think they are stupid when they make errors. This, in turn, encourages students to respect their own and each other's intelligence.

\section{Keeping a Math Journal}

Journals are an effective means of reducing students' math anxiety. They serve as vents for feelings and act as concrete records of progress for students who, too often, belittle their own successes and focus on what they cannot do. The journal helps students realize that they can now accomplish what one month ago they thought was impossible and helps them clarify which learning techniques worked best. Students are expected to write in their journals for five to ten minutes, three to four times a week. Topics vary: how they feel in class, how they attempt to do the homework, how they use math outside school, how they feel about their progress, and so on. I collect the journals frequently and comment on them. My comments offer encouragement, alternative solutions or perspectives, and explanations of how students' remarks on learning math often apply to learning in general. Students' comments on the class are very helpful for my lesson planning. I find time to read and comment on journals when I don't collect homework assignments but instead give students the answers to homework problems and encourage them to work on them in class and evaluate their learning together.

\section{Quizzes}

I start most lessons with a review and a one- or twoquestion quiz. I correct the quiz in class while students solve class-work problems, return the quiz, and review it immediately. The quizzes tell me which topics the students understand and which topics confuse them. They give the students a clear message about what they were expected to learn from the previous lesson. Also, giving students many quizzes then discussing feelings about taking tests, the fairness of the questions, and techniques for working under pressure gradually diminish their test anxieties. In addition, when end-term grades are required, an abundance of quiz grades can be helpful to students. 


\section{Students Teaching}

In order to teach a math problem to someone, you must be able to recognize all the correct methods of solving it as well as the logic behind incorrect methods. At the beginning of the term, I have students explain problems at the board and then, after discussing the difference between explaining and teaching, I gradually train them to teach. As various students practice teaching, they begin to involve many other students and to ask them to justify their answers. I remain quiet; the class checks itself and rarely lets a mistake go by. The students get very involved, arguing constructively and thinking creatively about solutions to the problems. The student teachers effectively involve even the quiet students, who are more willing to participate when it helps a classmate. A feeling of solidarity develops in the class as students, learning from each other, come to respect one another. After many students have had a chance to teach problems at the board, the class attitude begins to reflect their greater understanding of my role as teacher. Students realize how difficult it is to think on one's feet, to write at the board, and to talk to people who aren't paying attention. Having students teach helps break down the authoritarian image of the teacher and simultaneously builds true respect for the hard job good teachers do.

\section{Students Working in Groups}

In order for the class to work in groups, certain understandings need to be developed: that people learn at different rates, that they learn by asking questions and analyzing their mistakes, and that every problem can be solved in several correct ways. While the class works in small groups, I circulate among them to facilitate cooperation and to help students who are ahead realize that they can learn by sharing their knowledge.

I suggest a structure for group tasks by writing the task breakdown, with times, on the board, and having the class evaluate how the groups worked after each assignment. The following are sample group tasks:

\section{Group Evaluation of Homework}

(a) (five min.)Working in groups of three or four, determine which homework problem was easiest.

(b) (five min.) Determine which homework problem was hardest.

(Evaluating homework questions is a good lead into having students create their own math problems. Also, this task shows students that because people learn in different ways they find different problems easy or hard.)

\section{Group Creation of Quizzes}

(fifteen min.) Working in groups of three or four, create two quiz questions based on the previous lesson. I will then choose from your questions to create today's quiz.

(Once students learn to create fair, comprehensive test questions, they will be able to anticipate the test questions teachers will ask and therefore be able to study effectively for tests. Hopefully, the more practice students have in creating questions, the more they will become used to asking questions, in school and in their daily lives.)

\section{FINAL NOTE}

I must stress that although I have been developing this curriculum for six years, it is still far from finished. I want this course to be more than just a respectful alternative to the traditional, condescending arithmetic courses taught to adults. I want this course to radicalize students and move them to action. There are two potential underlying problems with which I am currently grappling: that, as with any "reform," there is the danger the course goals might lose their radical focus and become blended into traditional, liberal educational innovation; and that the course curriculum might create overwhelming pessimism in students.

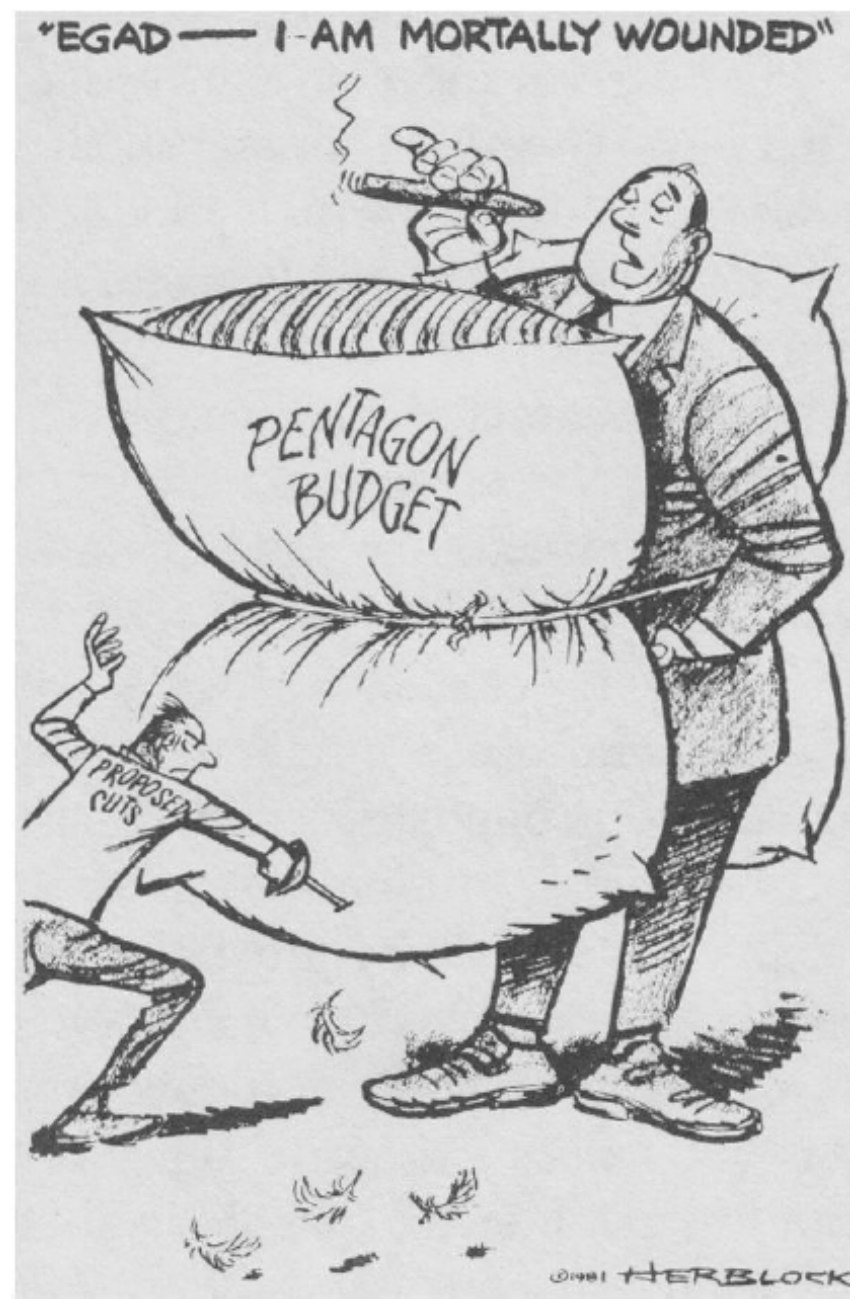

In the future, I would like to add to the course quantitative data showing victories that have been won. I would like students to complete an action project arising from quantitative data they collect on an issue that concerns them. The project must be small enough in scope to have a real chance of success, so it does not wind up reinforcing the childhood message of inherent impotence which, as Jonathan Kozol points out, is so effectively learned in school."10

A radical math course can help students focus and document their criticisms of life under capitalism. But, I am now convinced that it is vitally important for radical educators to offer more than just a critical analysis of 
society. I welcome suggestions about how we can also help give students the hope and the energy to act.

NOTES

1. Dollars and Sense (July-August, 1979), p. 7 (their source: Census Bureau, Current Population Reports, P-60 series); Dick Cluster, Nancy Rutter, and the staff of Dollars and Sense, Shrinking Dollars, Vanishing Jobs (Boston: Beacon, 1980), p. 28; "Infant, Maternal, and Neonatal Death Rates, and Fetal Death Ratios, by Race: 1940 to 1977," Statistical Abstracts of the United States, no. 108, p. 75; Information Please Almanac, 1979, pp. 345, 347

2. Paulo Freire, Pedagogy of the Oppressed (New York: Seabury Press, 1970), ch. 2.

3. Paulo Freire, Cultural Action for Freedom (Cambridge, Mass.: Harvard Educational Review, 1970), p. 11.

4. As William Profriedt points out, just the opposite happens in most classrooms, where there exists "a silly neutralism in which teachers believe they are just presenting facts and avoiding opinions or value statements. They avoid value statements because . . they do not believe that such statements are susceptible to rational inquiry and verification. Of course in practice they are transmitting a set of values, but one which is not identified as such, and hence is not open to critical inquiry." "Socialist Criticisms of Education in the United States: Problems and Possibilities," Harvard Educational Review (November, 1980), p. 477.

5. I also use pure math patterns, puzzles, mathematical magic, and mathematical art to add some recreational interest to the course.

6. Pedagogy of the Oppressed, p. 68.

7. These examples are not all current. I chose them to illustrate the range of political applications and the types of critical, creative thinking involved in the curriculum. Also, the examples are not in order of difficulty, and they are longer and seem somewhat harder to solve than when presented as part of a gradual buildup over a whole semester.

8. Cultural Action for Freedom, p. 44.

9. Other examples of error patterns can be culled from your teaching experiences or found in Robert B. Ashlock's Error Patterns in Computation (Columbus, Ohio: Charles E. Merrill, 1976).

10. Kozol summarizes this message of powerlessness: "Ask, and you may rest assured that you will be refused, but you will have done as much as you should, or as much as anybody has the right to ask, by the very fact of making the request." The Night Is Dark and I Am Far From Home (New York: Bantam, 1975), p. 98.

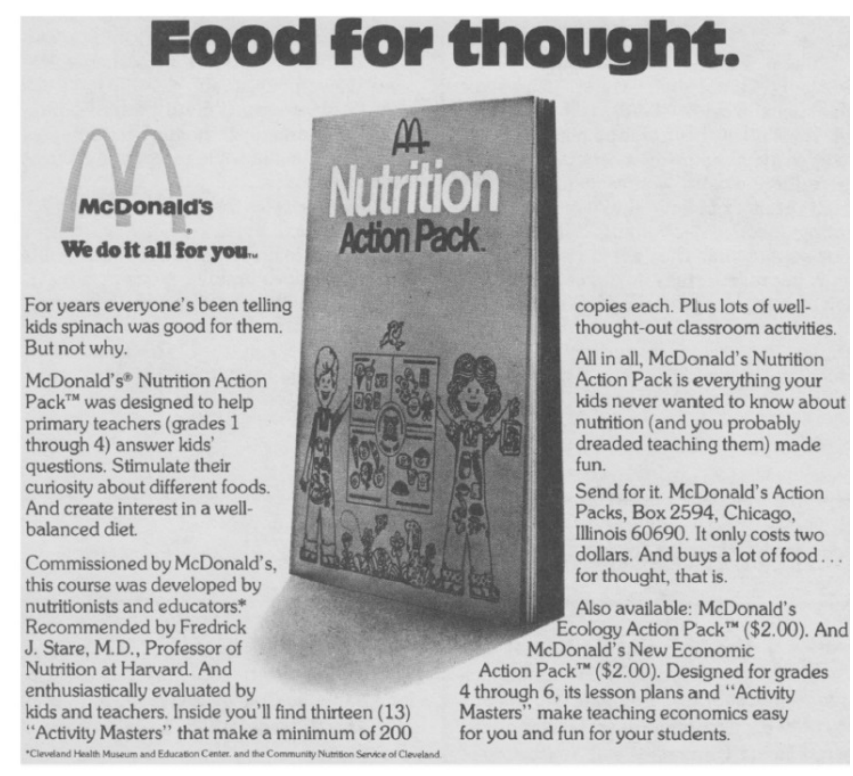

